\title{
Application of Rhodium-Catalyzed Cyclohydrocarbonylation to the Syntheses of Enantiopure Homokainoids
}

\author{
Wen-Hua Chiou $†, \S$, Angèle Schoenfelder ${ }^{\ddagger}$, André Mann $\ddagger$, and Iwao Ojima ${ }^{\dagger}$ \\ $\dagger$ Department of Chemistry, State University of New York at Stony Brook \\ * Faculté de Pharmacie, Université Louis Pasteur Strasbourg, France
}

\begin{abstract}
Kainic acid, rigidified $(S)$-glutamic acid, is a well-known kainite receptor agonist for the excitatory transmission in the central nerve system. Our interest in highly selective kainite ligands, prompted us to design a series of new kainic homologues, "homokainoids", i.e., conformationally rigidified (S)-glutamic acids. For the syntheses of enantiopure novel homokainoids (pipecolinoglutamic acids), we successfully applied cyclohydrocarbonylation $(\mathrm{CHC})$ reaction that has been developed in these laboratories. Efficient total syntheses of enantiopure novel homokainoids from $(R)$-serine feature the highly diastereoselective conjugate addition and the regioselective $\mathrm{CHC}$ process in the key steps.
\end{abstract}

\section{INTRODUCTION}

$(S)$-Glutamate mediates fast excitatory transmission at the majority of the central nervous system of mammalian synapses and also participates in neuronal plasticity and neurotoxicity [1-3]. Glutamate exerts its effects through activation of ligand-gates cation channels (the ionotropic glutamate receptors: iGluRs) [4] and/or metabotropic glutamate receptors (mGluRs) [5]. Glutamate receptors have attracted considerable attention because of their therapeutic potential for the treatment of a range of chronic and acute CNS disorders such as stroke, epilepsy, Alzheimer and Parkinson disease. Although glutamate is a nonselective agonist for the GluRs, it was extensively used as templates for the design of selective ligands. Examination of the chemical structures of the GluR ligands reveals that most of them have been developed by the introduction of conformational rigidity, which is a common strategy in medicinal chemistry [6].

Kainic acid (KA) represents a typical example for the concept of Glu rigidification [7,8]: the glutamate structure is embedded within a pyrrolidine ring, with an isopropenyl substituent at the C-4 position for probable additional hydrophobic interaction [9]. Numerous structureactivity relationship studies disclosed that the C-4 stereochemistry, the nature of the substituent and its conformation play a critical role in its binding to the GluRs [10]. On the basis of this hypothesis, various ligands have been developed by modifying the KA structure or the Glu structure for structure activity relationship studies [11]. A six-membered ring (i.e., piperidine) is conformationally more rigid than the corresponding five-membered ring (i.e., pyrrolidine) due to the relative high energy cost between chair-boat interconversion [12], which should contribute to the discovery of highly selective ligands for the KA receptor with greater stability and entropic gain. In addition, it is reasonable to assume that the introduction of a methyl or a

Correspondence to: Iwao Ojima.

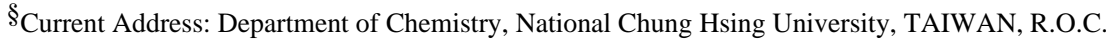


phenyl group at C-4 or C-5 would mimic the isopropenyl appendage in KA. Accordingly, we have designed a series of homokainic acids as homologues of KA as shown in Scheme 1.

Our strategy for the syntheses of these homokainates utilizes the diastereoselective conjugate addition [13] to establish the stereochemistry at the C-3 position and the cyclohydrocarbonylation reaction (CHC reaction) to construct the piperidine moiety with proper functional groups $[14,15]$.

\section{RESULT AND DISCUSSION}

\section{Synthesis of 3-Pipecolinoglutamic Acid (1)}

Scheme 2 illustrates the synthetic route to $(2 S, 3 R)$-3-pipecolinoglutamatic acid (1). HornerWadsworth-Emmons olefination of Garner's aldehyde 4, readily obtained from $R$-serine in a four-step sequence [16], with trimethyl phosphonoacetate afforded acrylate 5 in $93 \%$ yield $(E / Z=6 / 1)$. Since both $E$ and $Z$ isomers of 5 have given the same syn adduct $\mathbf{6}$, separation of the two products is unnecessary. Highly diastereoselective conjugate addition of lithium divinylcuprate to 5 gave syn product $\mathbf{6}$ ( $N$-Boc group to vinyl group) exclusively in $88 \%$ yield. The observed stereochemical course of this conjugate addition is consistent with a Felkin-Anh model in that the attack on the $R e$ face should take place to afford the observed product [13]. Deprotection of oxazolidine $\mathbf{6}$ under acidic conditions followed by acetylation gave the key intermediate 7 in $94 \%$ overall yield. Cyclohydrocarbonylation of $\mathbf{7}$ catalyzed by $\mathrm{Rh}$ (acac) $(\mathrm{CO})_{2}$-BIPHEPHOS $(0.25 \mathrm{~mol} \%)$ proceeded smoothly at $75^{\circ} \mathrm{C}$ and 4 atm of $\mathrm{CO}$ and $\mathrm{H}_{2}$ (1:1) in toluene for $24 \mathrm{~h}$ to give didehydropiperidine $\mathbf{8}$ in $99 \%$ yield. Hydrogenation of $\mathbf{8}$ over $5 \%$ $\mathrm{Rh} / \mathrm{C}$ under $10 \mathrm{~atm}$ of hydrogen afforded piperidine 9 in excellent yield. The cyclohydrocarbonylation and hydrogenation steps were performed in a one-pot manner as well, which gave piperidine 9 quantitatively. The Seebach's transesterification protocol, i.e. $\mathrm{MeOH}$ DBU-LiBr, proceeded smoothly to give the corresponding primary alcohol 10. Subsequent TEMPO-catalyzed [17] oxidation of $\mathbf{1 0}$ with sodium hypochlorite gave the desired acid $\mathbf{1 1}$, which was methylated with diazomethane to afford dimethyl ester 12 in $92 \%$ yields for three steps. Finally, 12 was refluxed in $6 N$ hydrochloric acid, followed by treatment with propylene oxide to give homokainoids 1 (55\% overall yield from Garner's aldehyde 4). The enantiomer of $\mathbf{1}$, i.e., $(2 R, 3 S)$-3-pipecolinoglutamatic acid (ent-1) was synthesized through the same procedure but starting from $(S)$-serine.

\section{Synthesis of 5-Phenyl-3-Pipecolinoglutamic Acid (2a)}

Scheme 3 illustrates the synthesis of (2S,3R,5S)-5-phenyl-3-pipecolinoglutamic acid (2a). (E)-4-Phenylbut-3-enylcarbamate 7a was prepared through Heck reaction of $\mathbf{7}$ with iodobenzene under the standard conditions in $83 \%$ yield.

Cyclohydrocarbonylation of 7a was performed using $\mathrm{Rh}(\mathrm{acac})(\mathrm{CO})_{2}-\mathrm{P}(\mathrm{OPh})_{3}$ at $75{ }^{\circ} \mathrm{C}$ and 120 atm of $\mathrm{CO}$ and $\mathrm{H}_{2}$ (1:1) to give 5-phenyldidehydropiperidine 8a in 96\% isolated yield. The result indicates that the hydroformylation of the styrene moiety afforded exclusively $\alpha$ formyl product, which underwent subsequent cyclization and dehydration to give $\mathbf{8 a}$. Hydrogenation of 8a over $\mathrm{Pd}(\mathrm{OH})_{2} / \mathrm{C}$ at ambient temperature and pressure proceeded with extremely high diastereoselectivity to give (5S)-phenylpiperidine $\mathbf{9 a}$ as a single diastereomer. The stereocenter at the C-5 position was assigned unambiguously based on the clear ROESY correlation between H-3 and H-5. To complete the synthesis of $\mathbf{2 a}$ from 9a, the same protocol described for the synthesis of $\mathbf{1}$ was applied through 12a, to afford homokainoid 2a. This synthesis was achieved in 5 steps from 7 in $57 \%$ overall yield. 


\section{Synthesis of 5-Methyl-3-Pipecolinoglutamic Acid (2b)}

In order to introduce a methyl group at the $\mathrm{C}-5$ position of pipecolinoglutamic acid, we envisioned two possible routes, i.e. (i) cyclohydrocarbonylation of an $\omega$-methyl-7 and (ii) Vilsmeier reaction followed by reduction of the resulting aldehyde. We anticipated that cyclohydrocarbonylation of an internal alkene would result in a regioselectivity problem in the hydroformylation step. Therefore, we chose the Vilsmeier-reduction approach. The Vilsmeier reaction of 5,6-didehydropiperidine was reported to give a 5-formyldidehydropiperidines [18]. Scheme 4 illustrates the synthesis of 5-methyl-3-pipecolinoglutamic acid (2b).

Reaction of didehydropiperidine 8 with Vilsmeier reagents followed by treatment with sodium acetate gave aldehyde 13. The formyl group of $\mathbf{1 3}$ was converted to 1,3-dithiolane $\mathbf{1 4}$. Subsequent desulfurization by Raney-Ni under 50 atm of $\mathrm{H}_{2}$ provided a 3:1 mixture of 5methyldidehydropiperidine $\mathbf{8 b}$ and 5-methylpiperidine $\mathbf{9 b}$. After removal of the solid Raney$\mathrm{Ni}$ catalyst, hydrogenation of $\mathbf{8 b}$ and $\mathbf{9 b}$ was carried out over $\mathrm{Pd} / \mathrm{C}$ in $\mathrm{MeOH}-\mathrm{AcOH}$ (30:1) to afford 5-methylpiperidine 12b as a single diastereomer in 68\% overall yield from $\mathbf{1 3 .}$

The configuration at the C-5 position was assigned unambiguously to $R$ on the basis of the ROESY correlation between H-3 and H-5. Subsequent transformations described for the synthesis of $\mathbf{1}$ was applied to complete the synthesis of homokainoid $\mathbf{2 b}$ ( $42 \%$ overall yield from 8 ).

\section{4-Methyl-3-pipecolinoglutamic acid (3)}

For the synthesis of 4-methyl-3-pipecolinoglutamic acid (3), we employed cyclohydrocarbonylation of oxazolidine 15 bearing a gem-disubstituted alkenyl moiety since the regioselectivity of the hydroformylation of this olefin moiety was guaranteed to be exclusive for the formation of the corresponding terminal aldehyde. However, the diastereoselectivity issue at the $\mathrm{C}-4$ position needed to be addressed by experiment. To synthesize 15, we used Lipshultz's procedure [19] to generate the corresponding high order cuprate because transmetallation of tetraisopropenyltin to the corresponding cuprate with $\mathrm{MeLi}$ was not successful. Thus, lithium diisopropenylcyanocuprate was prepared by reacting tetraisopropenyltin with freshly prepared $\mathrm{Me}_{2} \mathrm{CuCNLi}_{2}$. Subsequent conjugate addition of acrylate $\mathbf{5}$ proceeded smoothly to give syn adduct $\mathbf{1 5}$ exclusively in $91 \%$ isolated yield.

We hypothesized that either improvement of diastereoselectivity of the hydroformylation step or separation of two diastereomers might be possible by rigidifying the substrate for cyclohydrocarbonylation. Accordingly, lactone 16 was prepared by hydrolysis and lactonization under acidic conditions. Cyclohydrocarbonylation of lactone $\mathbf{1 6}$ was performed using $\mathrm{Rh}(\mathrm{acac})(\mathrm{CO})_{2}$-BIPHEPHOS at $75^{\circ} \mathrm{C}$ and 120 atm of $\mathrm{CO}$ and $\mathrm{H}_{2}(1: 1)$ to give bicyclic didehydropipecolinolactone $\mathbf{1 7}$ in nearly quantitative yield as a ca. 1:1 mixture of two diastereomers, which were readily separable by flash column chromatography. NOE analyses of the two epimers have revealed that the less polar diastereomer has $S$ configuration at the $\mathrm{C}-4$ position, i.e. the methyl group is $\beta$ and equatorial, while the more polar diastereomer has an axial methyl at the C-4 position, i.e., $R$ configuration. Hydrogenation of lactones $17 \boldsymbol{\alpha}$ and $17 \boldsymbol{\beta}$ over $\mathrm{Rh} / \mathrm{C}$ in methanol at ambient temperature and pressure afforded $18 \boldsymbol{\alpha}$ and $\mathbf{1 8 \beta}$, respectively. Subsequent transformations, described for the synthesis of 1 were applied to complete the syntheses of homokainoids $\mathbf{3 \alpha}$ (74\% from $\mathbf{1 7 a}$ ) and $\mathbf{3 \beta}$ ( $81 \%$ from $\mathbf{1 7 b}$ ).

\section{SUMMARY}

We successfully synthesized enantiopure homokainoids, $\mathbf{1}$, ent $\mathbf{- 1}, \mathbf{2 a}, \mathbf{2} \mathbf{b}, \mathbf{3} \boldsymbol{\alpha}$ and $\mathbf{3 \beta}$, featuring the extremely diastereoselective syn conjugate addition of an organocuprate to oxazolidinylacrylate 5 and the Rh-catalyzed cyclohydrocarbonylation 7, 7a and $\mathbf{1 7}$ in the key 
steps. Further studies on the biological evaluation of the homokainoids are actively underway in these laboratories.

\section{References}

1. Collingridge GL, Lester RAJ. Pharmacol Rev 1989;41:143-210. [PubMed: 2558391]

2. Nakanishi S. Science 1992;258:597-603. [PubMed: 1329206]

3. Riedel G. Trends Pharmacol Sci 1996;19:219-224.

4. Bleakman D, Lodge D. Neuropharmacology 1998;37:1187-1204. [PubMed: 9849657]

5. Pin JP, Duvoisin R. Neuropharmacology 1995;34:1-26. [PubMed: 7623957]

6. Mann, A. The Practice of Medicinal Chemistry. Wermuth, CG., editor. Elsevier; New York: 2003. p. 233-250.

7. McGeer, EG.; Olney, JW.; McGeer, PL. Kainic acid as a Tool in Neurobiology. Raven Press; New York: 1978.

8. Nielsen PA, Liljefors T. J Comput-Aided Mol Des 2001;15:753-763. [PubMed: 11718479]

9. Armstrong N, Sun Y, Guo-Qiang C, Gouaux E. Nature 1998;359:913-917. [PubMed: 9804426]

10. Parsons AF. Tetrahedron 1996;52:4149-4174.

11. Baldwin JE, Bamford SJ, Fryer AM, Rudolph MPW, Wood ME. Tetrahedron 1997;53:5233-5290.

12. Kumar VA, Ganesh KN. Acc Chem Res 2005;38:404-412. [PubMed: 15895978]

13. Jako I, Uiber P, Mann A, Wermuth CG, Boulanger T, Norberg B, Evrard G, Durant F. J Org Chem 1991;56:5729-5733.

14. Ojima I, Tzamarioudaki M, Eguchi M. J Org Chem 1995;60:7078-7079.

15. Ojima I, Vidal ES. J Org Chem 1998;63:7999-8003.

16. Garner P, Park JM. J Org Chem 1987;52:2361-2364.

17. Anelli PL, Biffi C, Montanari F, Quici S. J Org Chem 1987;52:2559-2562.

18. Shono T, Matsumura Y, Tsubata K, Sugihara Y, Yamane S, Kanazawa T, Aoki T. J Am Chem Soc 1982;104:6697-6703.

19. Behling JR, Babiak KA, Ng JS, Campbell AL, Moretti R, Koerner M, Lipshutz BH. J Am Chem Soc 1988;110:2641-2643. 

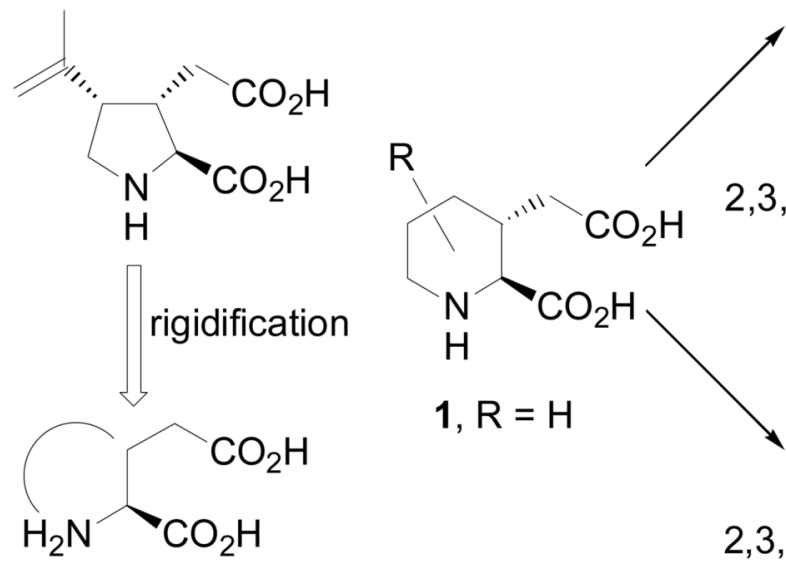

$\mathrm{R}$

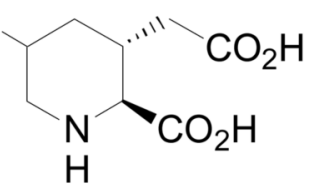
2a $(R=M e) ; 2 b(R=P h)$.<smiles>[R]C1CCNC(C(=O)O)C1CC(=O)O</smiles>

2,3,4-trisubstituted pecolinoglutamic acid 3a $(\mathrm{R}=\mathrm{Me})$

Scheme 1.

Kainic Acid and Homokainic Acids 

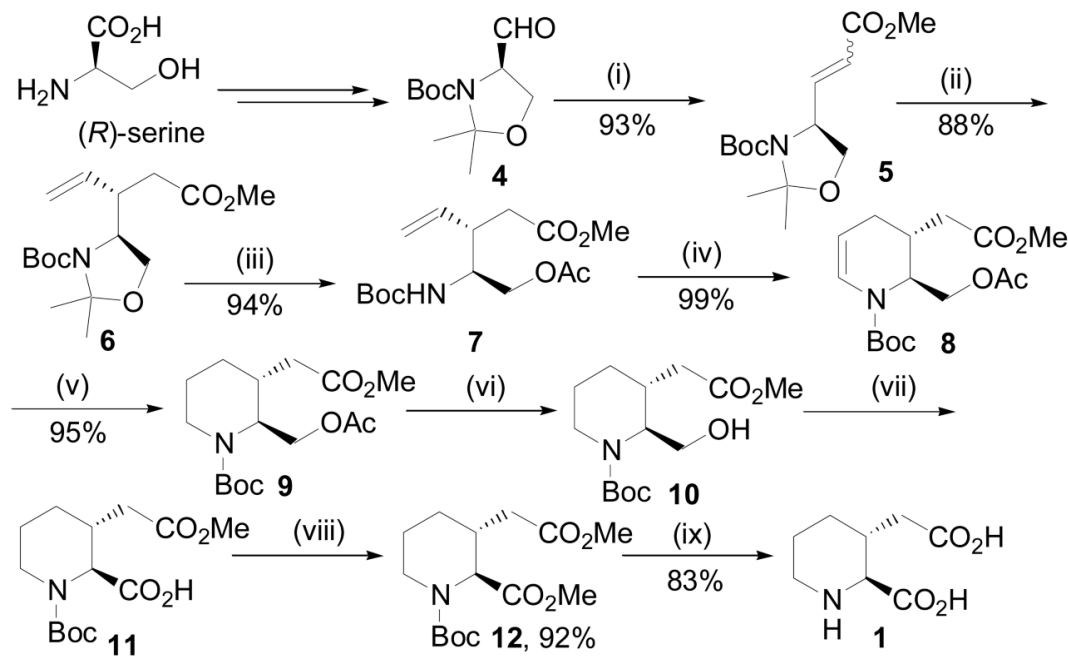

\section{Scheme 2.}

Synthesis of Homokainoid 1.

(i) $(\mathrm{MeO})_{2} \mathrm{P}(\mathrm{O}) \mathrm{CH}_{2} \mathrm{CO}_{2} \mathrm{Me}$, TBAI, $\mathrm{K}_{2} \mathrm{CO}_{3}, \mathrm{RT}$, (93\%). (ii) $\mathrm{LiCu}\left(\mathrm{CH}=\mathrm{CH}_{2}\right)_{2}, \mathrm{TMSCl}, \mathrm{Et}_{2} \mathrm{O}$, $-78^{\circ} \mathrm{C}$ to RT, (88\%). (iii) (a)PTSA ( $12.5 \mathrm{~mol} \%$ ) MeOH, RT, (b) excess $\mathrm{Ac}_{2} \mathrm{O}$-pyridine, (94\%). (iv) $\mathrm{Rh}(\mathrm{acac})(\mathrm{CO})_{2}(0.25 \mathrm{~mol} \%)$, BIPHEPHOS $(0.50 \mathrm{~mol} \%)$, toluene, $\mathrm{H}_{2}(2 \mathrm{~atm}) \mathrm{CO}(2 \mathrm{~atm})$, $75^{\circ} \mathrm{C}$, (99\%). (v) 5\% Rh-C, $\mathrm{H}_{2}$ (10 atm), $\mathrm{MeOH}$, RT. (95\%). (vi) DBU, LiBr, $\mathrm{MeOH}, \mathrm{RT}$.

(vii) TEMPO, $\mathrm{KBr}, \mathrm{NaOCl}$, acetone- $\mathrm{NaHCO}_{3(\mathrm{aq}}$, $4{ }^{\circ} \mathrm{C}$. (viii) $\mathrm{CH}_{2} \mathrm{~N}_{2}, \mathrm{MeOH}$. (92\% from 9). (ix) (a) $6 \mathrm{~N} \mathrm{HCl(aq),} \mathrm{RT,} \mathrm{overnight.} \mathrm{(b)} \mathrm{EtOH-} \mathrm{propylene} \mathrm{oxide,} \mathrm{reflux.} \mathrm{(83 \% )}$ 


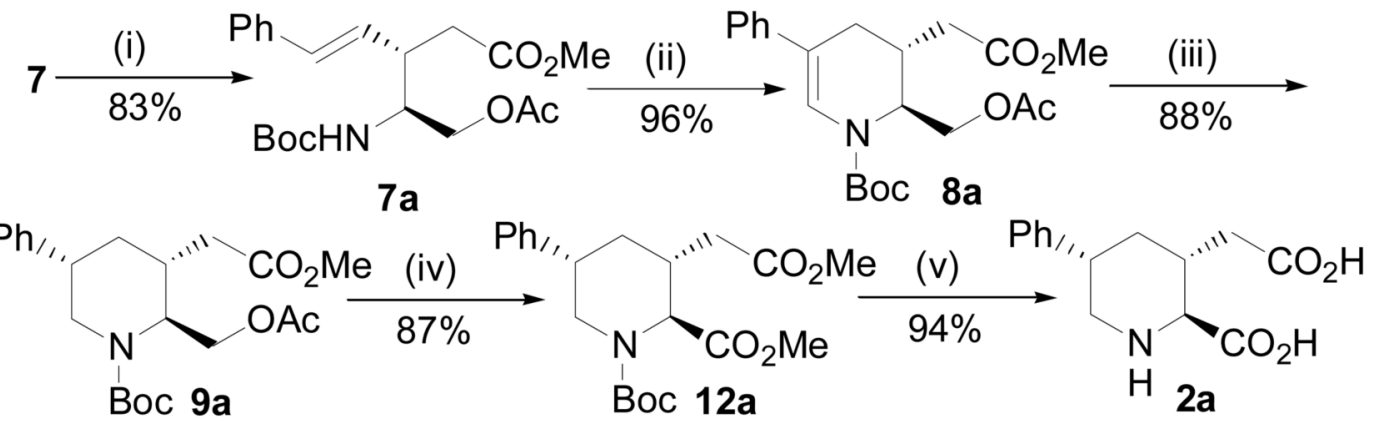

Scheme 3.

Synthesis of Homokainoid 2a.

(i) $\mathrm{Pd}(\mathrm{OAc})_{2}(5 \mathrm{~mol} \%), \mathrm{PPh}_{3}(10 \mathrm{~mol} \%), \mathrm{Et}_{3} \mathrm{~N}$ (3 eq) $\mathrm{PhI}(3 \mathrm{eq}), \mathrm{DMF}, 75^{\circ} \mathrm{C}, 4 \mathrm{~d}(83 \%)$. (ii) $\mathrm{Rh}(\mathrm{acac})(\mathrm{CO})_{2}(2 \mathrm{~mol} \%), \mathrm{P}(\mathrm{OPh})_{3}(8 \mathrm{~mol} \%)$, toluene, $\mathrm{H}_{2}(60 \mathrm{~atm}) \mathrm{CO}(60 \mathrm{~atm}), 75^{\circ} \mathrm{C}, 3 \mathrm{~d}$ (96\%). (iii) $\mathrm{Pd}(\mathrm{OH})_{2}(5 \mathrm{~mol} \%), \mathrm{H}_{2}, \mathrm{MeOH}, \mathrm{RT},(88 \%)$. (iv) (a) DBU, LiBr, MeOH, RT, (b) TEMPO, $\mathrm{KBr}, \mathrm{NaOCl}$, acetone- $\mathrm{NaHCO}_{3(\mathrm{aq})}, 4{ }^{\circ} \mathrm{C}$. (c) $\mathrm{CH}_{2} \mathrm{~N}_{2}, \mathrm{MeOH}$. (87\% from 9a). (v) (a) $6 \mathrm{~N} \mathrm{HCl}(\mathrm{aq}), \mathrm{RT}$, overnight. (b) EtOH- propylene oxide, reflux. (94\%) 


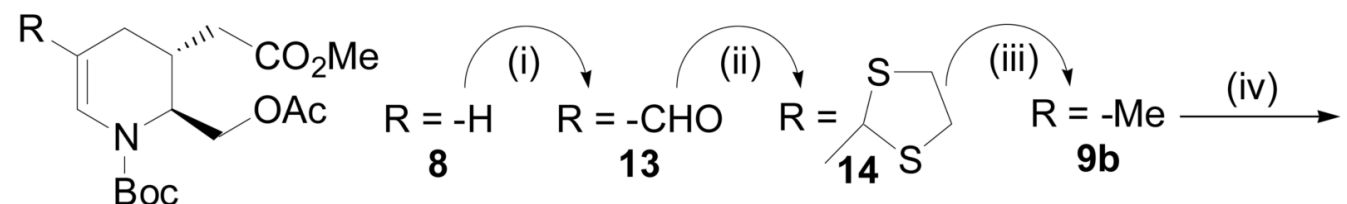

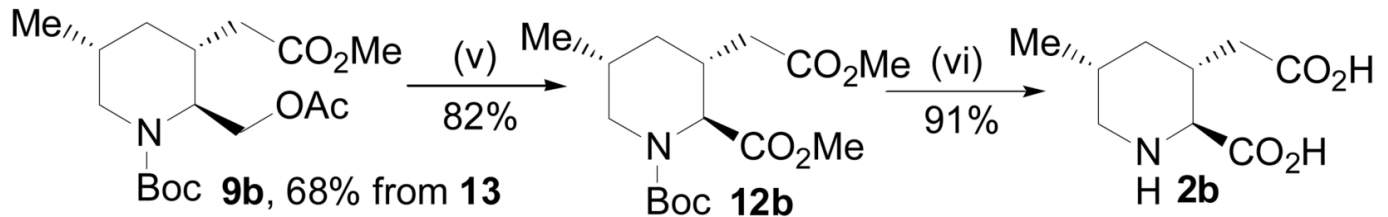

Scheme 4.

Synthesis of Homokainoid $\mathbf{2 b}$.

(i) (a) $\mathrm{POCl}_{3}$ (1.5 eq), DMF (1.5 eq), DCE, RT, 6 h, (b) $\mathrm{NaOAc}_{(\mathrm{aq})}$ reflux. (83\%) (ii)

$\left(\mathrm{CH}_{2} \mathrm{SH}\right)_{2}(1.1 \mathrm{eq}), \mathrm{PTSA}(10 \mathrm{~mol} \%), \mathrm{CHCl}_{3}$, RT. (iii) Raney-Ni, $\mathrm{H}_{2}$ (50 atm), RT, overnight. (iv) $\mathrm{Pd} / \mathrm{C}\left(5 \mathrm{~mol} \%\right.$ ), $\mathrm{H}_{2}$ (10 atm), MeOH-AcOH, RT. (68\% from 13). (v) (a) DBU, LiBr, MeOH, RT, (b) TEMPO, $\mathrm{KBr}, \mathrm{NaOCl}$, acetone- $\mathrm{NaHCO}_{3(\mathrm{aq})}, 4{ }^{\circ} \mathrm{C}$. (c) $\mathrm{CH}_{2} \mathrm{~N}_{2}, \mathrm{MeOH}$. (82\% from 9b). (vi) (a) $6 \mathrm{~N} \mathrm{HCl}(\mathrm{aq}), \mathrm{RT}$, overnight. (b) $\mathrm{EtOH}-$ propylene oxide, reflux. (91\%) 


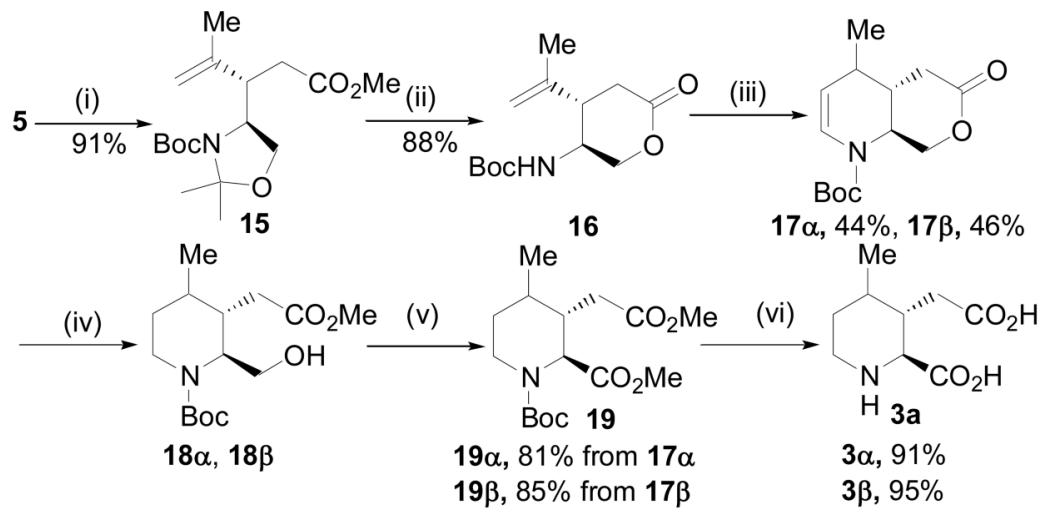

Scheme 5.

Syntheses of Homokainoid $\mathbf{3} \boldsymbol{\alpha}$ and $\mathbf{3 \beta}$

(i) $\mathrm{Li}_{2} \mathrm{CuCN}\left(\mathrm{CMe}=\mathrm{CH}_{2}\right)_{2}, 2 \mathrm{eq}, \mathrm{THF}-40 \sim 50{ }^{\circ} \mathrm{C}, 2 \mathrm{~h},(91 \%)$ (ii) (a) PTSA $(12.5 \mathrm{~mol} \%) \mathrm{MeOH}$, $\mathrm{RT}$, then Dean-Stark in $\mathrm{C}_{6} \mathrm{H}_{6}(87 \%)$. (iii) $\mathrm{Rh}(\mathrm{acac})(\mathrm{CO})_{2}(5 \mathrm{~mol} \%)$, toluene, $\mathrm{H}_{2}(60 \mathrm{~atm}) \mathrm{CO}$ (60 atm), $75^{\circ} \mathrm{C}, 48 \mathrm{~h}$, (iv) $5 \% \mathrm{Rh}-\mathrm{C}\left(5 \mathrm{~mol} \%\right.$ ), $\mathrm{H}_{2}$ (10 atm), MeOH, RT. (v) (a) TEMPO, KBr,

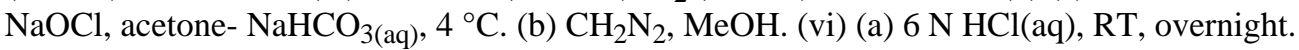
(b) EtOH- propylene oxide, reflux. 